\title{
ANÁLISES FíSICO-QUÍMICAS E DA PUREZA DO EXTRATO SECO DE Piper methysticum G. Forster (KAVA-KAVA)
}

\section{PHYSICO-CHEMICAL ANALYSES AND PURITY ANALYSES OF DRY EXTRACT OF PIPER METHYSTICUM G. FORSTER.}

\author{
Seilin Cardoso Justo ${ }^{1 *}$; Chana de Medeiros da Silva ${ }^{2,3}$ \\ ${ }^{1}$ Acadêmica do Curso de Farmácia, Universidade de Santa Cruz do Sul - Avenida \\ Independência no 2293, 9685-900, Santa Cruz do Sul - RS - Brasil. \\ seilinjusto@yahoo.com.br \\ 2 Departamento de Biologia e Farmácia da UNISC. \\ ${ }^{3}$ Professora da disciplina de Farmacognosia da UNISC. \\ RECEBIDO: 10/02/08 \\ ACEITO: 18/02/2008
}

\begin{abstract}
RESUMO:
Piper methysticum G. Forster, popularmente conhecido como Kava-Kava, é originário das ilhas do Oceano Pacífico, estando entre os 10 fitoterápicos mais vendidos no Brasil, principalmente para o tratamento de ansiedade e insônia e como alternativa ao uso dos medicamentos benzodiazepínicos. O presente trabalho, em vista da carência de informações sobre esta planta, procurou desenvolver parâmetros que auxiliem no controle de qualidade do extrato seco da Kava, fornecendo dados que favoreçam e incentivem a elaboração de sua monografia farmacopéica, o que contribuirá para o uso mais seguro e eficaz deste fitoterápico. Como resultados, obteve-se a presença de compostos fenólicos no extrato seco da Kava; um teor de umidade de 4,3\%; $\mathrm{pH}$ e densidade com valores de 4,64 e 0,63 g/mL, respectivamente, e ausência de material estranho. O extrato seco apresentou-se com coloração amarelo-esverdeado, extremamente fino e com odor levemente adocicado, que quando em contato com a mucosa bucal provoca intensa salivação. Não foi possível obter-se resultados satisfatórios quanto ao teor de cinzas totais e ponto de fusão.
\end{abstract}

PALAVRAS-CHAVE: Piper methysticum, Kava-Kava, cavalactonas, controle de qualidade, fitoterápicos.

\begin{abstract}
:
Piper methysticum G. Forster, popularly known as Kava-Kava, is original of Ocean Pacific's islands, being among of the 10 phytotherapics more sold in Brazil, mainly for the treatment of anxiety and insomnia and as alternative to the use of the benzodiazepinics medicines. The present work, in view of the lack of information on this plant, tried to develop parameters to aid in the quality control of the dry extract of Kava, supplying data that favor and motivate the elaboration of its monograph pharmacopeia, which will contribute to the safest and most effective use of this phytotherapic. As results, was obtained the presence of compounds phenolics in the dry extract of Kava; a tenor of humidity of $4.3 \%$; $\mathrm{pH}$ and density with values of 4.64 and $0.63 \mathrm{~g} /$ $\mathrm{mL}$, respectively, and absence of strange material. The dry extract came with yellow-greenish coloration, extremely fine and with slightly odour sweetened, that when in contact with the buccal mucous membrane provokes intense salivation. Was not possible to obtain satisfactory results to for the tenor of total ashes and melting point.
\end{abstract}

KEY WORDS: Piper methysticum, Kawa-Kawa, Kavalactones, quality control, phitotherapics. 


\section{INTRODUÇÃO}

A utilização de plantas como fonte de medicamentos remonta à idade antiga (CALIXTO, 2001) e vem evoluindo ao longo dos anos, desde as formas mais simples, aplicadas pelos homens pré-históricos, chegando aos medicamentos fitoterápicos utilizados hoje em dia, sendo que estes têm nas plantas medicinais importantes fontes de compostos bioativos (LORENZI; MATOS, 2002; RIBEIRO et al., 2005). Atualmente, a utilização destes está em contínua e acelerada expansão em nível mundial (ARANTES et al., 2005; SOUZA; LIONZO; PETROVICK, 2006).

Porém, apesar da grande utilização dos fitoterápicos (STEFANELLO et al., 2006) poucos são os estudos que visam à comprovação de suas propriedades terapêuticas, qualidade, segurança e eficácia de uso (CALIXTO, 2001). A utilização indiscriminada destes produtos, devido à crença de que substâncias naturais são totalmente benéficas (OLIVEIRA; GONÇALVES, 2006), reforça a importância de conscientizar a população quanto ao uso racional destes medicamentos e reforçar o número de estudos científicos que forneçam parâmetros para seu controle de qualidade e de suas matérias-primas (MELLO et al., 2004; ARNOUS; BEINNER; SANTOS, 2005; CORDEIRO; CHUNG; SACRAMENTO, 2005).

Considerando o uso tão difundido dos fitoterápicos, torna-se necessário o estabelecimento de parâmetros úteis no controle da qualidade destes medicamentos (BARA et al., 2006). A garantia do uso seguro e eficaz envolve análises farmacognósticas básicas, passíveis de serem realizadas em qualquer tipo de estabelecimento, como avaliação da presença de matéria orgânica estranha, sujidades e insetos, características organolépticas e análises macro e microscópicas (ZAUPA et al., 2000), além de análises físico-químicas, de pureza, microbiológicas e cromatográficas da matéria-prima e do produto acabado, importantes para se alcançar um padrão de qualidade necessário a um fitoterápico (BARA et al., 2006).

Fitoterápicos a base de Piper methysticum G. Forster (Kava-Kava) são amplamente utilizados em todo o mundo, principalmente para o tratamento de ansiedade e insônia e, na maioria das vezes, sem orientação médica, constituindo risco para a saúde pública, devido aos vários relatos de hepatotoxicidade associados ao seu uso, falta de parâmetros para seu controle de qualidade e também, à falta de orientação e controle de uso (TUROLLA; NASCIMENTO, 2006).

A Kava (Figura 1) pertencente à família Piperaceae, é originária das ilhas do Oceano Pacífico, sendo que nos anos 80 foi introduzida na Austrália, onde se tornou droga de abuso e, a partir daí, passou a ser conhecida pelo resto do mundo (SHING, 1992) principalmente como opção no tratamento de ansiedade e insônia e como alternativa ao uso dos benzodiazepínicos, pois além de não causar dependência, não provoca os efeitos adversos típicos desta classe medicamentosa, como distúrbios cognitivos (SCHENKEL; GOSMANN; PETROVICK, 2001; MUNTE et al., 1993; PINTO et al., 2005). Atualmente, esta planta não cresce mais naturalmente, sendo que, seu cultivo se dá para fins comerciais (SCHÜLZ; HANSEL; TYLER, 2002). 

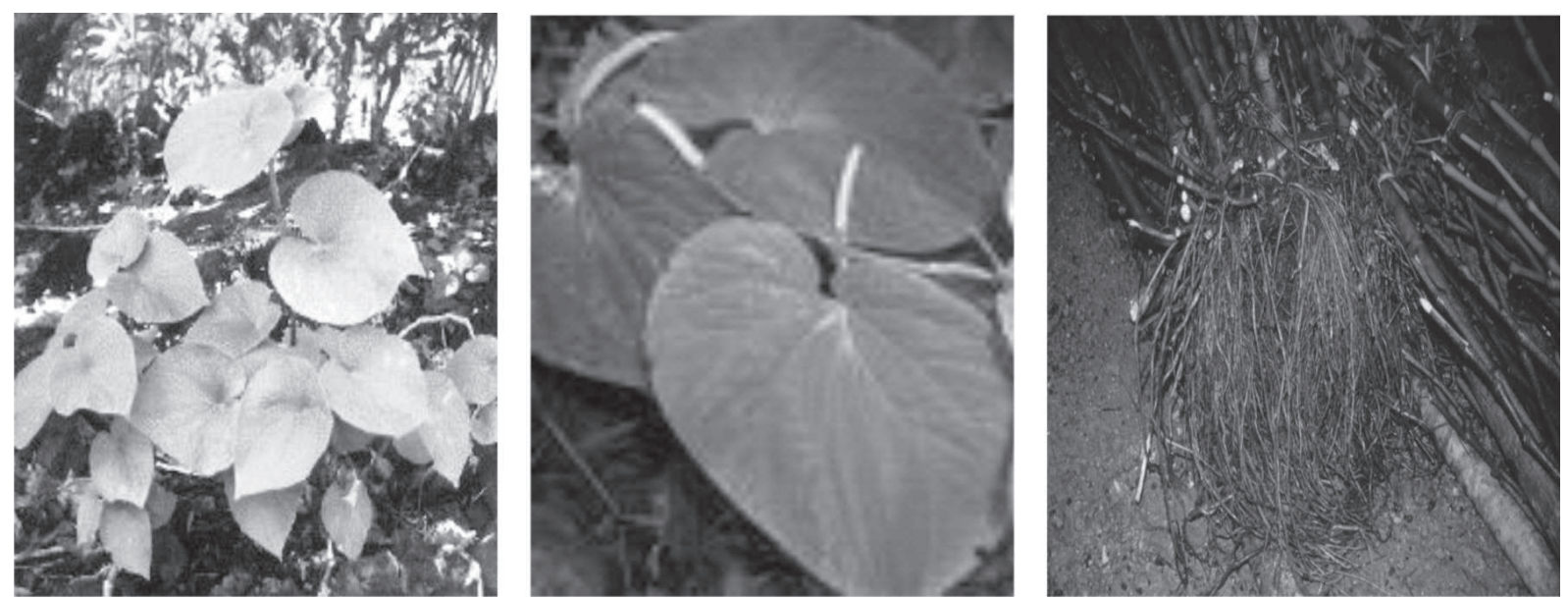

Figura 1: Aspectos da Kava. A - Aspecto geral; B - Detalhe das folhas; C - Rizoma.

Fonte: ZOU et al., 2004.

A espécie Piper methysticum apresenta em sua constituição química diversos constituintes, sendo eles o ácido benzóico, ácido cinâmico, alguns açúcares, bornilcinamato, estigmasterol, flavocavaínas, mucilagens, pironas, tetrahidroiangoninas e sais minerais, principalmente o potássio (CORDEIRO; CHUNG; SACRAMENTO, 2005). Segundo Cunha, Silva e Roque (2003), também são encontrados taninos na espécie. Porém, os principais constituintes da Kava-Kava, responsáveis por todas as suas atividades farmacológicas são as á-pironas (Figura 2), denominadas cavapironas ou cavalactonas (CORDEIRO; CHUN; SACRAMENTO, 2005).

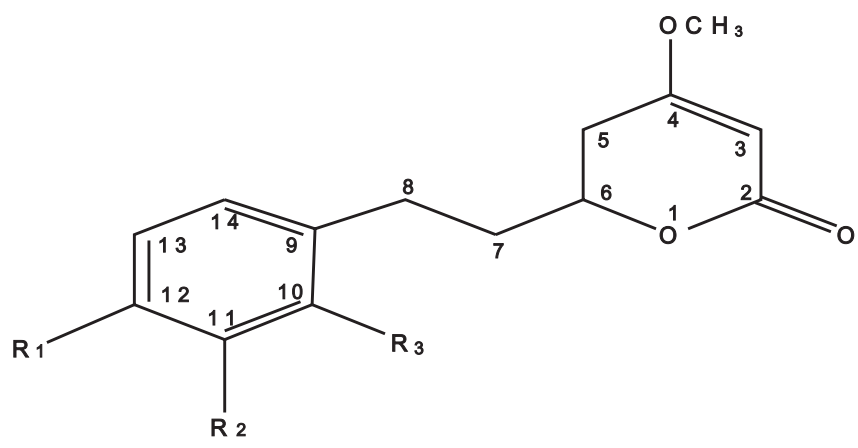

Figura 2: Estrutura geral das cavalactonas presentes em $P$. methysticum Fonte: ARRUDA et al., 2005.

Foram identificadas dezoito cavalactonas presentes na espécie $P$. methysticum, sendo que destas, as seis que apresentam maior importância farmacológica são a cavaína, iangonina, desmetoxiangonina, dihidrocavaína, metisticina e dihidrometisticina (PINTO et al., 2005). Estes compostos são encontrados no rizoma da planta, que é a droga vegetal (SCHÜLZ; HANSEL; TYLER, 2002). 
Seu mecanismo de ação, devido à diversidade de atividades farmacológicas relatadas (JAMIESON et al., 1989; BACKHAUSS; KRIEGLSTEIN, 1992; DAVIES et al., 1992; SINGH, 1992; GLEITZ; BEILE; PETERS, 1995; GARY PISCOPO, 1997; CAÑIGUERAL; VILA, 1998; UEBELHACK; FRANKE; SCHEWE, 1998; SCHIRRMACHER et al., 1999; UNGER et al., 2002; WU et al., 2002; HASHIMOTO et al., 2003; ANKE; RAMZAN, 2004; ZOU et al., 2004; ARRUDA et al., 2005; GARRETT et al., 2005), não permite uma explicação simples (SCHENKEL; GOSMANN; PETROVICK, 2001; YUAN, et al., 2002; CAIRNEY et al., 2003), sendo que, na literatura são encontrados dados muito contraditórios.

Esta planta, embora venha sendo usada de forma tão ampla pela população, ainda não possui monografia específica que descreva suas características, principalmente farmacológicas e farmacognósticas, o que acaba por contribuir com o grande problema que há muito ronda os fitoterápicos: a questão da qualidade, pois facilita processos de adulterações e/ou falsificações e, também, impede que um controle de qualidade mais rigoroso seja realizado.

Este trabalho, em vista do que já foi relatado, procurou obter dados que auxiliem e favoreçam o controle de qualidade do extrato seco da Kava, tais como prospecção fitoquímica, determinação do teor de umidade, determinação de cinzas totais, análise da presença de material estranho, análise sensorial, determinação do potencial hidrogeniônico $(\mathrm{pH})$, ponto de fusão e densidade, que possibilitem montar um banco de dados sobre o Piper methysticum, servindo de incentivo e suporte para a elaboração de sua monografia farmacopéica.

\section{MATERIAL E MÉTODOS}

Este trabalho foi realizado no Laboratório de Controle de Qualidade do Curso de Farmácia da Universidade de Santa Cruz do Sul - UNISC. Uma amostra de 30 gramas do extrato seco de P. methysticum, com concentração de $30 \%$ de cavalactonas, lote 8580 , foi adquirido aleatoriamente em uma farmácia de manipulação da cidade de Santa Cruz do Sul, RS.

Para todos os testes físico-químicos e de pureza realizados, utilizou-se 2 gramas do extrato seco em questão, que foi diluído em 100 mililítros de etanol $96 \%$ e armazenado em frasco âmbar.

\subsection{ANÁLISE SENSORIAL}

O extrato seco de Piper methysticum foi submetido a uma análise sensorial que englobou a análise do aspecto visual, do odor, da cor e do sabor do pó. Os três primeiros realizaram-se através de comparação com o laudo de análise que acompanha o extrato.

\subsection{ANÁLISES FÍSICO-QUÍMICAS}

Os testes fitoquímicos realizados visaram identificar as principais classes de compostos oriundos do metabolismo secundário da planta, sendo que as classes de 
substâncias testadas foram: compostos fenólicos, compostos antracênicos, flavonóides e taninos; para tanto, utilizou-se reações em tubo de ensaio em triplicata e cromatografia em camada delgada (CCD), segundo os métodos encontrados em Biavatti e Leite (2005) e Costa (2001).

Também se realizou testes que visaram identificar o $\mathrm{pH}$, o ponto de fusão e a densidade do extrato seco de P. methysticum (FARMACOPÉIA BRASILEIRAIV, 1988).

\subsection{VERIFICAÇÃO DA PUREZA}

A verificação da pureza do extrato seco da Kava baseou-se na pesquisa de material estranho, determinação de umidade através do método de perda por dessecação, e também, determinação de cinzas totais, sendo que, as duas últimas análises se deram em triplicata, seguindo-se os métodos descritos na Farmacopéia Brasileira IV (1988).

\section{RESULTADOS E DISCUSSÃO}

A análise sensorial do extrato seco de Piper methysticum está compreendida por análises do aspecto visual, sabor e cor, sendo isto, uma das etapas iniciais para seu controle de qualidade (OLIVEIRA; AKISUE; AKISUE, 1998; FARIAS, 2001). O extrato analisado mostrou-se extremamente fino, de cor amarelo-esverdeado, com odor bastante característico e levemente adocicado, que quando em contato com a mucosa bucal, causa muita salivação. Estes dados conferem com o laudo de análise obtido através do fornecedor, porém, na literatura, não existem tais dados, impossibilitando a comparação.

Na prospecção fitoquímica, o único composto oriundo do metabolismo secundário encontrado no extrato seco da Kava, foram os compostos fenólicos, posto que, na literatura, apenas a presença de taninos é relatada para a espécie (CUNHA; SILVA; ROQUE, 2003). Porém, seguindo a reação de Mello \& Santos (2001) para a identificação de taninos, ocorre precipitação do extrato após a adição da gelatina a $2 \%$, sendo isto um requisito inicial, contudo, não ocorre o desenvolvimento da coloração verde ou azul, não sendo possível a caracterização de taninos condensados e/ou hidrolisados. Entretanto, sabe-se que os compostos fenólicos, identificados no extrato, são precursores dos taninos, e que estes não se definem propriamente pela sua composição química, demasiadamente variável, mas por um conjunto de propriedades devidas, em maior parte, justamente à presença dos compostos fenólicos nas suas moléculas. Sendo assim, os taninos costumam ser identificados conforme a identidade dos compostos fenólicos nas suas moléculas (COSTA, 2002), e, sabe-se também, que a presença de etanol (utilizado para diluir o extrato) pode atrapalhar as reações de identificação dos taninos (MELLO; SANTOS, 2001). Sendo assim, é compreensível que a caracterização da classe de taninos presente no extrato seco da Kava tenha ficado comprometida.

As análises físico-químicas de densidade e $\mathrm{pH}$ apresentaram como resultados $0,63 \mathrm{~g} / \mathrm{mL}$ e 4,67, respectivamente, sendo que, estes dados conferem com o laudo de análise fornecido pelo distribuidor do extrato seco da Kava. O ponto de fusão da 
amostra em questão, com o equipamento utilizado, que alcança temperatura máxima de $300^{\circ} \mathrm{C}$, não foi encontrado. Contudo, acredita-se que, utilizando-se equipamento com capacidade superior ao utilizado, o ponto de fusão do extrato seja identificado. $\mathrm{Na}$ literatura pesquisada não existe tal dado, o que vem confirmar a carência de informações sobre esta planta que é tão utilizada mundialmente.

A amostra não acusava a presença de material estranho; porém, sabe-se que a maioria das pesquisas de impurezas realizadas com drogas vegetais relata a presença de um número excessivamente elevado de elementos estranhos à droga, sendo que, esse fato é o que vem a ser, geralmente, o motivo mais freqüente de desqualificação de amostras de origem vegetal (BIAVATTI; LEITE, 1996, DUARTE; BARDAL, 2002; AMARAL et al., 2003; CIRIO et al., 2003; DUARTE; LIMA, 2003; MELO et al., 2004).

Sabe-se que o excesso de água em matérias-primas vegetais facilita a ação de enzimas e também o desenvolvimento de fungos e bactérias (BORGES; SIMÕES; SCHENKEL, 2005) e que o teor de umidade das mesmas é um índice importante de ser conhecido por relacionar-se com sua boa preparação e manutenção (COSTA, 2001). O teor de umidade encontrado para a amostra do extrato seco de Kava foi de $4,3 \%$, sendo que este valor é considerado baixo, pois está abaixo do mínimo estabelecido pela Farmacopéia Brasileira (2000), que estabelece valores entre 8 a $14 \%$ de umidade para matérias-primas vegetais. Não foram encontrados na literatura valores para comparação.

As cinzas totais incluem as derivadas de tecido vegetal, as chamadas cinzas fisiológicas, e as derivadas de materiais estranhos, especialmente areia e terra (FARMACOPÉIA BRASILEIRA IV, 1988). Os teores de cinzas totais em amostras vegetais permitem a verificação da presença de impurezas inorgânicas não-voláteis, que podem estar presentes como contaminantes (FARIAS, 2001). Entretanto, analisouse por duas vezes distintas o extrato seco da Kava quanto ao seu teor de cinzas totais; na primeira análise o extrato permaneceu na mufla a $450^{\circ} \mathrm{C}$ por 4 horas, não ocorrendo formação de cinzas (apresentou-se esbranquiçado); na segunda análise, deixou-se o extrato na mufla por 6 horas à mesma temperatura da análise anterior, obtendo-se resultado idêntico. Com base nisto, acredita-se que o extrato seco da Kava necessite de temperaturas mais elevadas para calcinar. Entretanto, seguindo-se o método preconizado pela Farmacopéia Brasileira (1988), a temperatura máxima que deve ser atingida durante a determinação do teor de cinzas é $450^{\circ} \mathrm{C}$.

\section{CONCLUSÃO}

Por meio deste trabalho, foi possível estabelecer alguns parâmetros para o controle de qualidade do extrato seco da Kava. Entretanto, salienta-se a grande necessidade de desenvolverem-se mais estudos que contribuam com o controle de qualidade desta espécie, favorecendo assim, a população em geral, que utiliza largamente este fitoterápico e também o desenvolvimento de monografia específica e posterior inclusão na Farmacopéia Brasileira, fornecendo então subsídios para seu controle de qualidade, visando garantir a segurança e a eficácia deste fitoterápico. 


\section{REFERÊNCIAS}

AMARAL, F. M. M. et al. Avaliação da qualidade de drogas vegetais comercializadas em São Luis/Maranhão. Revista Brasileira de Farmacognosia, v. 13, supl., p. 27-30, 2003.

ANKE, J. RAMZAN, I. Pharmacokinet and pharmacodynamic drug interactions with Kava (Piper methysticum Forst f.). Journal of Ethnopharmacology, v. 93, p. 153-160, ago. 2004.

ARANTES, M. C. B. et al. Estudo farmacognóstico do Cyperus rotundus L. Revista Eletrônica de Farmácia, v. 2, n. 2, p. 17-20, 2005.

ARNOUS, A. H.; BEINNER, R. P. C.; SANTOS, A.S. Plantas medicinais de uso caseiroconhecimento popular e interesse por cultivo comunitário. Revista Espaço para a Saúde, v. 6 , n. 2, p. 1-6, jun.2005.

ARRUDA, A. M. de. et al. Piper methysticum L. (Kava-Kava): Histórico do uso e aspectos taxonômicos, farmacológicos e toxicológicos. Revista em Ciências da Saúde, n. 2, p. 59-68, 2005.

BACKHAUSS, C. KRIEGLSTEIN, J. Extract of Kava (Piper methysticum) and its methysticin constituents protect brain tissue against ischemic damage in rodents. European Journal Pharmacology, v. 14, n. 215, p. 265-269, mai. 1992.

BARA, M. T. F. et al. Determinação do teor de princípios ativos em matérias-primas vegetais. Revista Brasileira de Farmacognosia, v.16, n.2, abr./ jun. 2006.

BIAVATTI, M. W.; LEITE, S. N. Práticas de Farmacognosia, Itajaú: Univali, 2005.

LEITE, S.N. Avaliação da qualidade de chás medicinais e aromáticos comercializados em Itajaí - SC. Revista Brasileira de Farmacognosia, v.5, n.2, p. 175-184, 1996.

BOON, H. S.; WONG, A. H. C. kava: a test case for Canada's new to natural health products. Canadian Medical Association Journal, v. 169, n.11, p. 1163, nov. 2003.

BORGES, D. B.; FARIAS, M. R.; SCHENKEL, E. P. Comparação das metodologias da Farmacopéia Brasileira para determinação de água em matérias-primas vegetais, e validação da determinação de água em analisador de umidade para Calendula officinalis L..; Foeniculim vulgare Miller, Maytenus ilicifolia Mart. Ex. Reissek e Passiflora alata Curtis. Revista Brasileira de Farmacognosia, v. 15, n. 3, p. 229-236, jul./set. 2005.

CALIXTO, João Batista. Medicamentos Fitoterápicos. In: YUNES, R. A.; CALIXTO, J. B. Plantas medicinas - sob a ótica da química medicinal moderna. Chapecó: Argos, 2001. 
CARNEY, S. et al. Saccade and Cognitive Function in Chronic Kava Users. Neuropsychopharmacology, n. 28, p.389-396, 2003

CIRIO, G. M. et al. Interrelação de parâmetros agronômicos e físicos de controle de qualidade de Maytenus ilicifolia, Mart. Ex. Reiss (espinheira-santa) como insumo para a indústria farmacêutica. Visão Acadêmica, v. 4, n. 2, p. 67-76, jul./dez. 2003.

CORDEIRO, C. H. G.; CHUNG, M. C.; SACRAMENTO, L. V. S. Interações medicamentosas de fitoterápicos e fármacos: Hypericum perforatum e Piper methysticum. Revista Brasileira de Farmacognosia, v.15, n.3, p.272-278, jul./set.2005.

COSTA, Aloísio Fernandes. Farmacognosia Experimental. 3. ed. Lisboa: Fundação Calouste Gulbenkian, 2001, v. 3.

Aloísio Fernandes. Farmacognosia. 5 ed. Lisboa: Fundação Calouste Gulbenkian, 2002. v. 1.

CUNHA, A. P.; SILVA, A.P.; ROQUE, O. R. Plantas e produtos vegetais em fitoterapia. Lisboa: Fundação Calouste Gulbenkian, 2003.

DAVIES, L. P. et al. Kava pyrones and resin: studies on GABA-A, GABA-B and benzodiazepine binding sites in rodent brain. Pharmacology and Toxicology, v. 71, n. 2, p. 120-126, ago. 2004.

DUARTE, M.R.; BARDAL, D. Qualidade de amostras de fármacos vegetais comercializados em Curitiba-PR. Visão Acadêmica, v. 3, n. 2, p. 65-68, jul./dez. 2002.

; LIMA, M. P. Análise farmacopéica de amostras de camomila. Visão Acadêmica, v. 1, n. 2, p. 73-82, 2003.

DUVE, R. N. Gas-liquid chromatography determination of major constituents of Piper methysticum. Analyst. v.106, p. 160-165, fev. 1981.

FARIAS, M. R. et al. O problema da qualidade dos fototerápicos. Caderno de Farmácia, v. 1, n. 2, p. 73-82, 1985.

FARMACOPÉIA, Brasileira. 4. ed. São Paulo: Editora Atheneu, 1988.

. 4. ed. São Paulo: Editora Atheneu, 2002.

GARRET, K. M. et al. Extracts of Kava (Piper methysticum) induce acute anxiolytic-like behavioral changes in mice. Psychopharmacology, n. 170, p.33-41, jul.2003.

GLEITZ, J.; BEILE, A.; PETERS, T. (+/-) - Kavain inhibits veratridine-activated voltagedependent $\mathrm{Na}(+)$ - channels in synaptosomes prepared from rat cerebral cortex. Neuropharmacology, v. 34, n. 9, p. 1133-1138, set. 1995. 
HASHIMOTO, T. et al. Isolation and synthesis of TNF-á release inhibitors from Fijian Kawa (Piper methysticum). Phytomedice, n.10, v. 4, p. 309-317, maio de 2003.

JAMIESON, D.D. et al. Comparison of the central nervous system activity of the aqueous and lipid extract of Kava (Piper methysticum). Archives internationales de pharmacodinamie et de therapie, n. 301, p. 66-80, set./out. 1989.

LORENZI, H.; MATOS, F.J.A. Plantas medicinais no Brasil: nativas e exóticas cultivadas. Nova Odessa: Instituto Plantarum, 2002.

MELLO, J. G. de. Avaliação da qualidade de amostras comerciais de boldo (Peumus boldus Molina), pata-de-vaca (Bauhinia spp.) e ginco (Ginkgo biloba L.). Revista Brasileira de Farmacognosia, v. 14, n.2, p. 111-120, 2004.

MELLO, J. C. P. de. SANTOS, S. C. Taninos. In: SIMÕES, C. M. O. et al. . Farmacognosia: da planta ao medicamento. 3 ed. Porto Alegre/Florianópolis: Ed. Da UFRGS/ Ed UFSC, 2001, p. 527 - 554.

MUNTE, T. F. et al. Effects of oxazepam and an extract of Kava roots (Piper methysticum) on event-related potentials in a word recognition task. Neuropharmacology, v. 27, n. 1, p. 46-53, 1993.

OLIVEIRA, F.; AKISUE, G.; AKISUE, M. K. Farmacognosia. São Paulo: Editora Atheneu, 1998.

OLIVEIRA, F.Q.; GONÇALVES, L.A. Conhecimento sobre plantas medicinais e fitoterápicos e potencial de toxicidade por usuários de Belo Horizonte, Minas Gerais. Revista Eletrônica de farmácia, v. 3, n.2, p. 36-41, 2006.

PINTO, V. M. et al. Avaliação do uso de Piper methysticum quanto ao desenvolvimento de hepatotoxicidade em ratos Wistar. Veterinária em Foco, v. 3, n. 1, p. 21-26, mai. / dez. 2005.

RIBEIRO, P. A. M. et al. Controle de qualidade físico-químico de matérias-primas vegetais. Revista Eletrônica de Farmácia, v. 2, n. 2, p. 176-179, 2005.

SCHENKEL, L. C.; GOSMANN, G.; PETROVICK P. R. Produtos de origem vegetal e o desenvolvimento de medicamentos. In: SIMÕES, C. M. O. et al. Farmacognosia: da planta ao medicamento. 3 ed. Porto Alegre/Florianópolis: Ed. da UFRGS/Ed. da UFSC, 2001, p. 301-330.

SCHIMIDT, A.H.; MOLNAR, I. Computer-assisted optimization in the developed of a high-performance liquid-chromatography method for the analysis of Kava pyrones in Piper methysticum, v. 978, p. 51-63, mar. 2002. 
SCHÜLZ, V.; HANSEL, R.; TYLER, V. E. Fitoterapia Racional- Um guia de fitoterapia para as ciências da saúde. $4 \square$ ed. Barueri: Manole, 2002.

SINGH, Y. N. Kava; an overview. Journal of Ethnopharmacology, n. 37, p. 13-45, 1992.

SOUZA, T. P. de; LIONZO, M. I. Z.; PETROVICK, P. R. Avaliação da redução da carga microbiana de droga vegetal através do processamento tecnológico: decocção e secagem por aspersão. Revista Brasileira de Farmacognosia, v.16, n.1, p. 94-98, jan./ mar. 2006.

STEFANELLO, M. E. A. et al. Avaliação da atividade antimicrobiana e citotóxica de extratos de Gochnatia polymorpha ssp floccosa. Revista Brasileira de Farmacognosia, v. 16, n. 4, p. 525-530, out./dez. 2006.

TUROLLA, M. S.; NASCIMENTO, E. S. Informações toxicológicas de alguns fitoterápicos utilizados no Brasil. Revista Brasileira de Ciências Farmacêuticas, v. 42, n. 2, p. 289306, abr./jun.2006.

UEBELHACK, R., FRANKE, L., SCHEWE, H. J. Inhibition of platelet MAO-B by Kava pyrone-enriched extract from Piper methysticum Forster (Kava-kava). Pharmacopsycheatry, v. 31, n. 5, p. 187-192, set. 1998.

UNGER, M. et al. Inhibition of Cytochrome P4503A4 by extracts and kavalactones of Piper methysticum (kava-Kava). Planta Médica, n. 68, p. 1055-1058, 2002.

WU, D. et al. Cyclooxygenase enzyme inhibitory compounds with antioxidant activites from Piper methysticum (Kava Kava) roots. Phytomedice, v. 9, n.1, p. 41-47, jan. 2002.

YUAN, C. S. et al. Kavalactones and Dihidrokavain Modulate GABAergic Activity in a Rat Gastric-Brainstem Preparation. Planta Médica, v. 68, p. 1092-1096, 2002.

ZAUPA, C. et al. Controle de qualidade: farmacobotânico e legal de fitoterápicos comercializados nas farmácias de Maringá (PR). Revista Racine, ano x, p. 32-36, set./ out. 2000.

ZOU, L. et al. Effects of Kava (kava-kava, 'Awa, yangona, Piper methysticum) on cDNA- expressed cytochrome P450 enzymes and human cryopreserved hepatocytes. Phytomedice, v.11, n. 4, p. 285-294, abr. 2004. 